\title{
Strain to evaluate ventricular function in Fontan patients undergoing exercise cardiac magnetic resonance imaging
}

\author{
Shafkat Anwar ${ }^{1 *}$, Ravi Doddasomayajula ${ }^{1}$, Marc S Keller $^{3}$, Matthew A Harris ${ }^{1}$, Ajit Yoganathan², Mark A Fogel', \\ Kevin K Whitehead ${ }^{1}$
}

From 17th Annual SCMR Scientific Sessions

New Orleans, LA, USA. 16-19 January 2014

\section{Background}

Feature tracking strain (FTS) is a new technique to assess cardiac function from cardiac magnetic resonance (CMR) images. We compared FTS with conventional function parameters in single ventricle subjects with Fontan physiology undergoing exercise CMR.

\section{Methods}

28 Fontan subjects (median age 16.6 years, $14 / 28$ morphologic left ventricle, 14/28 morphologic right ventricle) underwent a resting and exercise CMR. Standard high resolution, segmented balanced steady state free precession (SSFP) images were acquired with breath holds at rest. Cartesian real time (RT) cine images were acquired at rest then repeated at exercise, targeting the HR at anaerobic threshold on a recent metabolic exercise stress test (EST). Ventricular volumes and cardiac output were calculated offline. Off-line strain analysis was performed (TomTec 2D CPA, v. 1.0) on the "4-chamber" and shortaxis views at basal, mid, and apical levels.

\section{Results}

At rest there was moderate correlation between global circumferential strain (GCS) and stroke volume (SV), Pearson $\mathrm{r}=0.48(\mathrm{p}=0.009)$ and cardiac index $(\mathrm{CI}), \mathrm{r}=$ $0.39(p=0.04)$, Figure 1 . There was also good correlation between resting GCS and exercise SV, $r=0.56(p=$ 0.002). During exercise there was good correlation between GCS, SV and cardiac output indexed to body surface area (SV/BSA, CI), $\mathrm{r}=0.45(\mathrm{p}=0.015)$ and $\mathrm{r}=$ $0.56, \mathrm{p}=0.002)$ respectively, Figure 2 . There was no

'Pediatrics, Cardiology, The Children's Hospital of Philadelphia, Philadelphia, Pennsylvania, USA

Full list of author information is available at the end of the article relationship between GCS and ejection fraction, end-diastolic volume or end-systolic volume at rest or exercise.

\section{Conclusions}

In single ventricle Fontan patients there is moderate correlation between strain and measures of ventricular output (SV and CI) at rest and exercise, but not directly to ventricular size or ejection. Further studies are required to determine the role of feature-tracking strain in the assessment of ventricular function. Analysis of regional strain may helpful in understanding myocardial mechanics in the single ventricle.

\section{Funding}

Dr Kevin K. Whitehead: NIH K23 Grant HL089647 from the National Heart, Lung and Blood Institute.

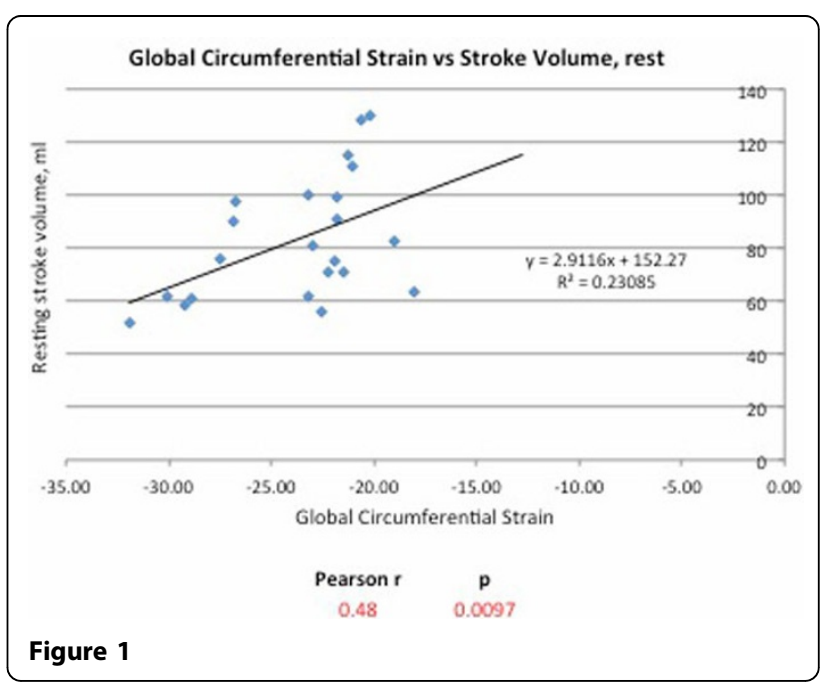




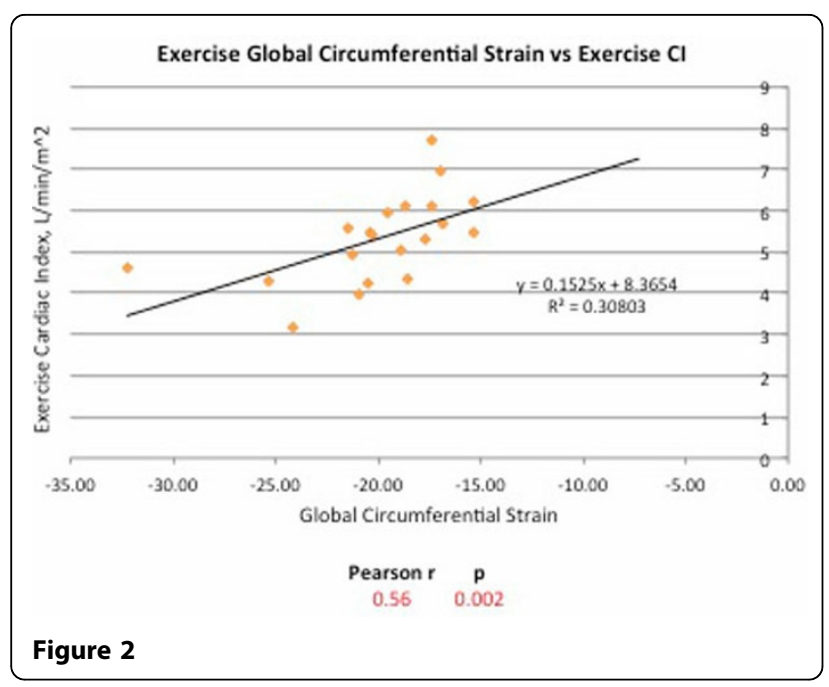

Dr. Mark Fogel: NIH R01HL098252-01, "Understanding mechanisms of Fontan failure and key predictors for patient outcome."

\section{Authors' details}

'Pediatrics, Cardiology, The Children's Hospital of Philadelphia, Philadelphia, Pennsylvania, USA. 'Biomedical Engineering, Georgia Institute of Technology, Atlanta, Georgia, USA. ${ }^{3}$ Pediatrics, Radiology, The Children's Hospital of Philadelphia, Philadelphia, Pennsylvania, USA.

Published: 16 January 2014

doi:10.1186/1532-429X-16-S1-P123

Cite this article as: Anwar et al: Strain to evaluate ventricular function in Fontan patients undergoing exercise cardiac magnetic resonance imaging. Journal of Cardiovascular Magnetic Resonance 2014 16(Suppl 1): P123.

\section{Submit your next manuscript to BioMed Central} and take full advantage of:

- Convenient online submission

- Thorough peer review

- No space constraints or color figure charges

- Immediate publication on acceptance

- Inclusion in PubMed, CAS, Scopus and Google Scholar

- Research which is freely available for redistribution

Submit your manuscript at www.biomedcentral.com/submit 